\title{
PROGRAMA TALENTO METRÓPOLE: novas trajetórias de desenvolvimento para jovens com Altas Habilidades/Superdotação
}

\author{
Juliana Teixeira da Camara Reis \\ Priscila Magalhães Barros Felinto \\ Izabel Hazin
}

Resumo

O estudo teve por objetivo analisar o impacto do programa Talento Metrópole (IMD-UFRN), o qual visa desenvolver o interesse de jovens com altas habilidades/superdotação (AH/SD) em pesquisa científica, além da ampliação das competências e habilidades, expansão da criatividade no campo da Tecnologia da Informação e suas interfaces com outras áreas do conhecimento, visando a inovação e o empreendedorismo. Trata-se de um estudo multicasos que contou com a participação de três jovens diagnosticados com AH/SD, com idades entre 18 e 24 anos, de ambos os sexos. O levantamento de dados se deu a partir de diferentes estratégias: entrevistas semiestruturadas e registros sistemáticos de observações comportamentais. As análises dos casos evidenciaram pontos de semelhança, bem como idiossincrasias comportamentais e emocionais relacionadas às vivências negativas na escola; e sofrimento psíquico em razão da ausência de suporte às suas necessidades educacionais especiais, - sendo a desmotivação, a queixa mais presente. Desse modo, programas especiais podem possibilitar oportunidades e atividades focadas nos interesses e necessidades dos sujeitos, de acordo com as diferentes formas de expressão das AH/SD. Este cenário é fundamental para a produção criativa e desenvolvimento, proporcionando assim, uma inserção social e profissional satisfatória que poderá trazer impactos relevantes para a sociedade.

Palavras-chave: tecnologia; inclusão; educação; altas habilidade; superdotação.

TALENTO METROPOLE PROGRAM: new development trajectories for young people with High Abilities

\begin{abstract}
The study aimed to analyze the impact of Talento Metrópole program (IMD-UFRN), which intends to develop the interest of young people with high abilities / giftedness in scientific research, as well as the broaden of competence and abilities, expansion of creativity in the area of Information Technology and its interfaces with other areas of knowledge, focused on innovation and entrepreneurship. This is a multi-case study with the participation of three young subjects diagnosed with high abilities/giftedness, aged between 18-24 of both genders. The data survey was based on different strategies: semi-structured interviews and systematic records behavioral observations. The analyses of the cases revealed points of similarity, as well as behavioral and emotional idiosyncrasies, related to negative experiences at school; and psychological suffering due to the lack of support to their special educational needs - demotivation being the most common complaint. In this way, special programs can enable opportunities and activities focused on the subjects' interests and needs, according to the different forms of expression of people with high abilities/giftedness. This scenario is fundamental for creative production and development, thus providing a satisfactory social and professional insertion that can bring relevant impacts to society.
\end{abstract}

Keywords: technology; inclusion; education; high abilities; giftedness. 
DOI: $10.12957 /$ teias.2021.57231

PROGRAMA TALENTO METRÓPOLE: nuevas trayectorias de desarrollo para jóvenes con Altas Habilidades/Superdotación

Resumen

Este estudio tuvo por objetivo analizar el impacto del programa: Programa Talento Metrópoli (IMDUFRN), el cual busca desarrollar el interés de los jóvenes con altas habilidades/superdotación (AH/SD) por la investigación científica, además de la expansión de competencias y habilidades, así como de la creatividad en el campo de las Tecnologías de la Información y sus interfaces con otras áreas del conocimiento, con el fin de la innovación y el espíritu empresarial. Se trata de un estudio de casos múltiples, con la participación de tres sujetos de entre 18 y 24 años, de ambos sexos. La recolección de datos se realizó por diferentes medios: entrevistas semiestructuradas y registros de observaciones conductuales. El análisis de los casos arrojó puntos de similitudes, así como idiosincrasias comportamentales y emocionales relacionadas con experiencias negativas en la escuela; y sufrimiento psíquico debido a la falta de apoyo a sus necesidades educativas especiales, siendo la desmotivación la queja más común. De esta forma, los programas especiales pueden posibilitar ambientes y oportunidades que brinden actividades enfocadas a los intereses y necesidades de los sujetos, de acuerdo con las diferentes formas de expresión de los AH/SD, un escenario adecuado es fundamental para la producción creativa y el desarrollo positivo, brindando así una inserción social y profesional satisfactoria que pueda traer impactos relevantes a la sociedad.

Palabras-clave: tecnología; inclusión; educación; altas habilidades/superdotación; asincronía del desarrollo.

\section{INTRODUÇÃO}

O interesse humano pela capacidade intelectual superior é antigo, e esteve comumente atrelado à evolução das pesquisas acerca da inteligência. Sendo assim, da mesma forma que há variações nas definições do construto inteligência, os conceitos de altas habilidades, superdotação e talento compõem uma miríade conceitual, sem que haja consenso teórico. Devido à complexidade inerente aos construtos citados, identifica-se um estado de fluxo contínuo inerente à área (MILLER, 2012).

Nas últimas décadas, os modelos teóricos de AH/SD sofreram amplas modificações. Tais teorias para além da inteligência, passaram a considerar aspectos funcionais e desenvolvimentais, bem como, mais recentemente, fatores emocionais. Ainda assim, uma análise geral das definições de AH/SD revela algumas posições teóricas antagônicas e até excludentes. De modo geral, alguns conceitos são mais restritivos e outros mais liberais em suas definições (MATTHEWS, FOSTER, 2005; MILLER, 2012).

Neste artigo será abordado o modelo proposto por Subotnik e colaboradores (2011), o qual desloca o foco da superdotação para o talento. Nesse sentido, torna-se essencial diferenciar estes dois construtos, sendo o primeiro associado às habilidades naturais excepcionais, enquanto o segundo implica desenvolvimento e conhecimento. Tal virada epistêmica foi inicialmente discutida por Tannenbaum (2003), Gagné (2009), Bloom (1985) e pela própria Subotnik e Jarvin (2005).

As concepções atuais de superdotação destacam seu caráter processual, ou seja, ela adquire características distintas ao longo do tempo, é mutável e as trajetórias individuais são únicas, com diferentes pontos de partida, picos e pontos finais (OLSZEWSKI-KUBILIUS, SUBOTINIK, WORRELL, 2015). O processo de desenvolvimento de talentos envolve estágios e transições a partir das quais o potencial é transformado em competência, a competência em expertise e a expertise em eminência (SUBOTNIK et al., 2011). 
O primeiro estágio, denominado potencial, é caracterizado pela oferta de estímulos variados e uma ampla gama de oportunidades, tendo como objetivo central incrementar as rotas de desenvolvimento e aprendizagem. Esse processo tem como principais protagonistas os pais, cuidadores e educadores dos anos iniciais que juntos podem ofertar experiências e ambientes convidativos e que promovam o engajamento e a curiosidade do jovem. Nesta fase é comum que a criança se envolva intensamente com temas específicos e/ou atividades de interesse peculiar (hiperfoco). Neste momento, a família e a escola devem encorajar a criança a aprofundar-se na temática, contribuindo para que ela adquira confiança e motivação para a realização de objetivos a longo prazo (SUBOTNIK, 2015).

O segundo estágio é caracterizado pelo movimento de transformação do potencial em competência. Para tanto, torna-se vital a aprendizagem, o estudo e a prática deliberados em áreas específicas de talentos socialmente reconhecidos. Tal etapa coincide com os anos finais do ensino fundamental e médio, quando os jovens têm ideias criativas e são capazes de identificar seus potenciais. No entanto, é preciso apoiar a identificação dos pontos de fragilidade, de modo a desenvolver estratégias de minimização ou superação desses pontos, o que será decisivo para o seu futuro. Nessa etapa, torna-se essencial que o jovem talentoso seja exposto a situações desafiadoras, que aprenda a lidar com situações de frustração e contratempos. Nesse período, o adolescente está desenvolvendo sua identidade, por essa razão, é importante o compartilhamento com os pares que comungam os mesmos interesses e potenciais, o contato com profissionais adultos (mentores) e pesquisadores, o que implica em motivação e aprofundamento dos saberes em sua área (ou áreas) de interesse.

O terceiro estágio, caracterizado pela transição da competência para a experiência (expertise) exige ultrapassar o conhecimento dos fundamentos de um domínio específico. Implica movimentos que possibilitem a socialização inicial na cultura de um determinado campo do saber, o que pode ser realizado através de trabalho cooperativo com outros profissionais, com tutores e com outros alunos talentosos. Nesta etapa, é fundamental conhecer pontos de força, mas igualmente reconhecer zonas de fragilidade, pois para além do desenvolvimento intelectual, é importante oportunizar o desenvolvimento de habilidades que favoreçam a comunicação e as habilidades sociais, tais como autoconfiança e capacidade de receber e responder críticas (SUBOTNIK, 2015). Por fim, destaca-se o movimento de transição da experiência para a eminência, que comumente ocorre na vida adulta, e caracteriza-se pela socialização sólida do indivíduo em um campo específico do conhecimento (SUBOTNIK, JARVIN, 2005; SUBOTONIK et al., 2011).

O modelo descrito de desenvolvimento de talentos tem como um dos seus pontos de força o potencial para oferta de oportunidades e orientações que atingem uma gama mais ampla de jovens, inclusive aqueles com baixa renda, e oportunidades de inserção em atividades culturais e ambientes linguísticos diversificados. Adicionalmente, é uma abordagem consistente com estudos recentes que sublinham a maleabilidade e o caráter processual da inteligência, assim como com a assunção do papel das oportunidades e de variáveis não-cognitivas para o sucesso acadêmico e profissional (OLSZEWSKI-KUBILIUS, THOMSON, 2015).

A partir do exposto, é preciso considerar que a proposição de um programa de desenvolvimento de talentos é dependente da vinculação entre os jovens e as universidades, centros de pesquisa, entre outros dispositivos sociais (OLSZEWSKI-KUBILIUS, THOMSON, 2015). Isso posto, considerando o modelo de enriquecimento e desenvolvimento de talentos anteriormente apresentado, foi desenvolvido o Programa Talento Metrópole da Universidade Federal do Rio Grande do Norte (UFRN), ressaltando sua importância no desenvolvimento de talentos no domínio da Tecnologia da Informação (TI). 


\section{PROGRAMA TALENTO METRÓPOLE (PTM)}

O PTM está diretamente vinculado ao Instituto Metrópole Digital, unidade acadêmica da Universidade Federal do Rio Grande do Norte. O programa possui uma estrutura básica composta por três semestres. Ao término desta fase inicial, o aluno pode optar por permanecer no programa, apresentando semestralmente um Plano Individual de Atividades. O plano deve refletir os interesses e a motivação do aluno. O objetivo é acompanhar continuamente o desenvolvimento do talento durante a sua formação nos diferentes níveis (técnico, graduação e pós-graduação).

Cabe ressaltar que o PTM prevê a possibilidade de os alunos cursarem disciplinas isoladas de outros níveis formativos, diferentes daquele no qual se encontra. Sendo assim, um aluno do ensino médio, por exemplo, pode cursar uma disciplina da graduação ou da pós-graduação. Outro aluno pode fazer simultaneamente a graduação e a pós-graduação, obtendo conjuntamente os dois graus. Tal iniciativa rompe com a rigidez do ensino tradicional, pouco adaptada para o perfil cognitivo e motivacional de alunos com AH/SD.

A sequência didática e a natureza das atividades ofertadas no PTM foram elaboradas a partir do Modelo de Desenvolvimento de Talentos (SUBOTNIK et al., 2011) e das diretrizes formativas da Sociedade Internacional para Tecnologia da Educação (International Society for Technology in Education - ISTE). São quatro matrizes que norteiam a proposição das três disciplinas regulares e das atividades complementares, sendo elas: Cidadania digital e colaboração; Pesquisa, gerenciamento de informações e comunicação; Pensamento crítico, flexível e inovador e; Resolução de problemas e pensamento computacional. A estrutura global do PTM é apresentada na Tabela 1, a seguir.

Tabela 1: Estrutura global do Programa Talento Metrópole

\begin{tabular}{|c|c|c|}
\hline Temáticas & Objetivos & Atividades Desenvolvidas \\
\hline $\begin{array}{l}\text { Semestre 1. O Mundo } \\
\text { da Tecnologia: } \\
\text { Ontem, Hoje e } \\
\text { Amanhã }\end{array}$ & $\begin{array}{l}\text { O objetivo maior é apresentar o } \\
\text { domínio da TI, identificando o } \\
\text { impacto das pesquisas vigentes. } \\
\text { Por outro lado, são apresentadas } \\
\text { áreas temáticas diversas, cujo } \\
\text { objetivo é ampliar os horizontes } \\
\text { de conhecimento. }\end{array}$ & $\begin{array}{l}\text { Os alunos participam de workshops e } \\
\text { palestras de temáticas diversas; realizam } \\
\text { visitas técnicas a laboratórios e núcleos de } \\
\text { pesquisa; acompanham mesas redondas } \\
\text { com temáticas contemporâneas debatidas } \\
\text { por pesquisadores de diferentes áreas do } \\
\text { conhecimento. }\end{array}$ \\
\hline $\begin{array}{l}\text { Semestre } 2 . \\
\text { Interdisciplinaridade e } \\
\text { Transversalidade em } \\
\text { Tecnologia da } \\
\text { Informação }\end{array}$ & $\begin{array}{l}\text { O objetivo maior é a } \\
\text { verticalização da produção de } \\
\text { conhecimento e a socialização no } \\
\text { campo da TI. Para tanto, aborda } \\
\text { a TI em interface com outras } \\
\text { áreas do conhecimento. O aluno } \\
\text { é convidado a desenvolver ideias } \\
\text { e soluções para problemas reais. }\end{array}$ & $\begin{array}{l}\text { Os alunos participam de oficinas e } \\
\text { minicursos sobre o uso de ferramentas e } \\
\text { conhecimentos específicos em TI. } \\
\text { Realizam visitas e interagem com } \\
\text { professores, pesquisadores e profissionais } \\
\text { de outras áreas do conhecimento que } \\
\text { desenvolvem projetos em interface com } \\
\text { as TIs. }\end{array}$ \\
\hline $\begin{array}{l}\text { Semestre 3. Pesquisa, } \\
\text { Inovação e } \\
\text { Empreendedorismo } \\
\text { em TI }\end{array}$ & $\begin{array}{l}\text { O objetivo maior é o } \\
\text { desenvolvimento de projetos de } \\
\text { pesquisa, extensão, inovação e } \\
\text { empreendedorismo. }\end{array}$ & $\begin{array}{l}\text { Os alunos devem selecionar o laboratório } \\
\text { e projeto de pesquisa nos quais irá } \\
\text { desenvolver as suas atividades. Estas } \\
\text { podem ser realizadas individualmente ou } \\
\text { em pequenos grupos, contando com a } \\
\text { tutoria de um professor pesquisador. }\end{array}$ \\
\hline
\end{tabular}

Fonte: Elaboração do autor 
A cada semestre os estudantes elaboram, junto com seu tutor, um Plano de Atividades contendo o cronograma de estudos e projetos a serem desenvolvidos. Estes planos devem refletir os seus interesses. Adicionalmente, realizam um conjunto de atividades que objetivam o desenvolvimento de habilidades sociais e criatividade. Dentre estas atividades, destacam-se o Cine Talento, o Clube de Arte e Leitura, a criação de uma Liga para participar de olimpíadas científicas em nível nacional e as visitas técnicas monitoradas à laboratórios, universidades, centros de pesquisa e empresas incubadas de outras cidades.

No Cine Talento, os alunos selecionam a temática de interesse e o coordenador do PTM escolhe um filme que aborde o assunto escolhido. Posteriormente, o coordenador compõe uma mesa com pesquisadores de áreas distintas que irão debater com os alunos aspectos centrais do filme selecionado. O Clube de Arte e Leitura, por sua vez, tem como foco a leitura e discussão de obras literárias e experiências artísticas em todas as suas formas de expressão.

A Liga das Olimpíadas tem como objetivo a preparação dos alunos para a participação nas diferentes olimpíadas do conhecimento, tais como robótica, matemática, astronomia, dentre outras. Nesta atividade, alunos mais experientes treinam e preparam os alunos mais novos. O PTM tem alcançado medalhas nacionais e internacionais, notadamente nas olimpíadas brasileiras de informática e robótica (OBI e OBR).

Durante as atividades de visitas técnicas, os membros do PTM entrevistam pesquisadores e profissionais da área de TI, a fim de conhecer novas realidades e desafios. A troca de experiências exitosas constrói um acervo de conhecimentos e subsídios para que, gradativamente, os próprios jovens possam propor seus projetos e ideias inovadoras. Os projetos provenientes dessas parcerias são apresentados em eventos científicos e publicados em artigos da área, alcançando reconhecimento nacional e internacional.

Atualmente, o PTM é composto por 30 alunos, com idades entre 12 e 24 anos, estudantes dos três últimos anos do ensino fundamental, do ensino médio e da graduação (este último nível exclusivo para alunos que ingressaram no programa anteriormente). O processo de identificação destes jovens é processual e complexo, envolvendo quatro etapas distintas que vão desde a capacitação de docentes que auxiliam na identificação dos candidatos ao programa nas escolas, passando pela avaliação ampliada da inteligência, motivação, criatividade e das habilidades e competências que compõem as matrizes mencionadas anteriormente, até à realização de curso constituído por oficinas temáticas de raciocínio lógico, pensamento computacional, programação e robótica. Simultaneamente os alunos realizam avaliação neurocognitiva, investigando domínios como: funcionamento executivo, visoespacialidade, memória e atenção.

Dentre os questionamentos inerentes à proposição de quaisquer programas de intervenção e desenvolvimento está aquele que se questiona acerca da eficácia e eficiência das propostas. E o que isto significa quando consideramos altas habilidades e desenvolvimento de talentos? Pode-se optar por resultados de provas e/ou testes formais, reconhecimento na área e conquistas ao longo dos anos (prêmios, seleções, medalhas). Porém, pode-se optar pela análise das trajetórias de desenvolvimento destes jovens, em especial avaliadas a partir das narrativas por eles produzidas e que evidenciam o lugar do programa, sua relevância e centralidade, ou não, no curso de suas vidas, bem como de que maneira a família e a escola cercearam ou incentivaram os seus talentos.

\section{O ESTUDO}

O presente estudo explorou as experiências vividas por três jovens (entre 18 e 24 anos), todos eles com patamares de inteligência, perfil de criatividade e desempenho em teste que avalia 
matrizes de habilidades e competências em TI definitivamente superiores à média normativa. Porém, cada um deles desenvolveu-se em um contexto específico de adversidade, a saber: a duplaexcepcionalidade AH/SD e Transtorno do Espectro do Autismo (TEA); a vulnerabilidade social e o transtorno do humor.

A premissa teórica subjacente a este estudo, de cunho qualitativo, é uma combinação do interpretativismo e da teoria afirmativa da deficiência. Essa escolha implica necessariamente assumir como objetivo maior dar visibilidade às experiências vividas por jovens duas vezes excepcionais. Por sua vez, a perspectiva interpretativista defende que o conhecimento é subjetivamente construído por pessoas em contextos sociais e culturais (YOUNG, 2009) e a pesquisa pode facilitar o entendimento dessas experiências através da interpretação (SCHWANDT, DENZIN, 1994).

Por fim, convém destacar que pessoas com trajetórias de desenvolvimento qualitativamente diferentes são atores ativos e suas idiossincrasias fazem parte de quem são. Portanto, eles não são o reflexo de um modelo médico de passividade, uma vez que possuem identidades, modos de agir e pensar que desafiam o status quo (RONKSLEY-PAVIA, GROOTENBOER, PENDERGAST, 2019). Nesse sentido, no presente estudo, não serão exploradas as características que rotulam a deficiência ou as fragilidades, mas as experiências dos participantes ao longo de suas trajetórias e como o PTM integra o curso das mesmas, considerando os estágios de desenvolvimento de talentos (SUBOTNIK, 2015). Para tanto, foram produzidas narrativas para dois eixos temáticos: Escola e Família e o Programa Talento Metrópole.

\section{A INVESTIGAÇÃO NARRATIVA}

A investigação narrativa fornece uma estrutura interpretativa para a compreensão das experiências de indivíduos (KIM, 2016). As metodologias narrativas reconhecem que as histórias de experiências vividas são forjadas através de práticas discursivas (RONKSLEY-PAVIA, GROOTENBOER, PENDERGAST, 2019). Além disso, utiliza-se as vozes e as próprias palavras dos participantes para recontar suas histórias. Consequentemente, a produção das narrativas aqui exploradas servirá de estrutura para interpretar as experiências vividas por cada um dos participantes (KIM, 2016).

Importante ressaltar que a natureza da pesquisa narrativa e o tamanho da amostra impedem que os dados sejam generalizados. As narrativas resultantes operaram como um processo de interpretação e reinterpretação de experiências, produzindo relatos que contam e recontam vidas vividas.

\section{Participantes}

Participaram da pesquisa três jovens integrantes do Programa Talento Metrópole, com idades entre 18 e 24 anos, sendo dois do sexo masculino e um do sexo feminino. Os participantes preenchem os critérios de identificação para Altas Habilidades/Superdotação para participarem do Programa Talento Metrópole, com patamares de inteligência, perfil de criatividade e desempenho em teste que avalia matrizes de habilidades e competências em TI definitivamente superiores à média normativa. Cada um dos participantes desenvolveu-se em um contexto específico de adversidade, sendo estes: a dupla-excepcionalidade (AH/SD) e Transtorno do Espectro do Autismo (TEA); a vulnerabilidade social e; o transtorno de humor. Em função dos critérios éticos que envolvem pesquisas com seres humanos, optou-se por substituir os nomes dos participantes 
por importantes pesquisadores e inovadores no campo da Tecnologia da Informação, personagens reconhecidos mundialmente.

Para atender aos princípios éticos da pesquisa todos autorizaram a publicação dos resultados a partir do assinado o Termo de Consentimento Livre e Esclarecido (TCLE) assinado. Além disso, foram criados pseudônimos, estes homenageiam importantes programadores do século XX, conforme caracterizados na Tabela 2.

Tabela 2: Caracterização dos participantes do estudo

\begin{tabular}{|c|c|c|c|c|}
\hline Sujeito & Idade & Escolaridade & Tipo de Escola & $\begin{array}{c}\text { Ano de } \\
\text { Ingresso no } \\
\text { Programa }\end{array}$ \\
\hline Allan Turing & 24 & Cursando Ensino Superior & $\begin{array}{c}\text { Universidade Pública } \\
\text { Federal }\end{array}$ & 2015 \\
\hline Bill Gates & 18 & Concluiu Ensino Médio & Escola Pública Estadual & 2018 \\
\hline $\begin{array}{c}\text { Margareth } \\
\text { Hamilton }\end{array}$ & 18 & Cursando Ensino Superior & $\begin{array}{c}\text { Universidade Pública } \\
\text { Federal }\end{array}$ & 2016 \\
\hline
\end{tabular}

Fonte: Elaboração do autor.

\section{PRINCIPAIS ACHADOS}

\section{Caso Clínico 1: Allan Turing - dupla-excepcionalidade AH/SD e TEA}

O termo dupla-excepcionalidade refere-se a uma condição na qual o indivíduo tem uma combinação de AH/SD com uma condição de deficiência, tais como os transtornos do neurodesenvolvimento e os transtornos de aprendizagem (NICPON, ASSOULINE, COLANGELO, 2013). Neste caso, em especial, a combinação envolveu AH/SD e Transtorno do espectro do Autismo (TEA).

O Caso Clínico 1 refere-se a um jovem, com anos 24 anos de idade, em seu último ano de formação no ensino superior. Allan Turing ingressou no PTM em 2015, com 20 anos de idade, cursando o $2^{\circ}$ ano da graduação em Tecnologia da Informação numa instituição pública federal. Allan Turing cursou o ensino fundamental e médio em escola particular. Atualmente, reside com os pais e um irmão caçula. Além da graduação, e da participação no programa, participa de atividades esportivas, aulas de música, além de atividades de pesquisa e extensão no âmbito universitário.

Allan tem interesses variados, escreve histórias e livros sobre dragões e cavalos, comumente presentes em literatura fantástica, e jogos de role-playing game (RPG). Ainda nessa temática desenvolve jogos e faz ilustrações de personagens que irão compor os seus universos. Em função da história criada, constrói personagens detalhados, com traços físicos e características psicológicas.

A produção narrativa de Allan Turing para o Eixo 1 de análise, ou seja, as vivências referentes à escola e a família, ressaltam o quanto ambos os contextos, em determinados momentos, cercearam o seu interesse pessoal em nome do atendimento às regras e aos objetivos propostos para a sua turma:

Teve algumas ocasiões em que ... o que eu queria... queria... eram mais questões daquele... de um livro específico... e eles reclamavam muito porque queriam um outro livro específico, de um autor específico, de uma marca específica, e eu queria aprender um pouco mais... um pouco mais. Até meus pais às vezes 
também incentivavam para eu focar no livro que a escola solicitou porque... porque é o que eles querem. Isso me inibiu um pouco e até hoje em dia, ainda me sinto um pouco receoso pra avançar... o que meus pais iriam pensar? Será que vai dar certo isso que vou fazer? Ou, se o que eu estou fazendo vai valer a pena? (sic).

De acordo com a perspectiva de desenvolvimento de talentos avançada por Subotnik e colaboradores (2018), o desenvolvimento de talentos específicos é uma pedra angular na trajetória das crianças, isto porque as habilidades fundamentais são maleáveis e precisam ser desenvolvidas, sob risco de serem perdidas ou atrofiadas (SUBOTNIK, OLSZEWSKI-KUBILIUS, WORRELL, 2018). Turim teve seus interesses cerceados desde muito cedo, num movimento de engessamento e uniformização que englobava até os livros a serem lidos e quais temáticas deveriam ser consideradas.

É salutar destacar que as habilidades em desenvolvimento começam, atingem o pico e finalizam suas trajetórias em diferentes idades. Por sua vez, para transformar potencial em realização é necessária a oferta de oportunidades de desenvolvimento, de modo que indivíduos talentosos sejam beneficiados com a proposição de tais cenários. O grande desafio da educação de talentos é preparar estes jovens que procuram mudar o mundo para transformar suas habilidades em contribuições criativas ou inovadoras (SUBOTNIK, OLSZEWSKI-KUBILIUS, WORRELL, 2018).

Nessa direção, o PTM parece ter ofertado a Allan Turing um espaço potencial de desenvolvimento e de uso criativo e produtivo de suas áreas e temáticas de interesse, conforme ele próprio narra:

Nos projetos do Talento eu estou inscrito em um projeto pessoal, que agora não é mais pessoal, que é o projeto do museu virtual, que vai ser um projeto que vai reunir a história do talento e talvez, posteriormente a história do Metrópole Digital. E também estou participando do Projeto Dagda, que é um projeto que consiste em fazer jogos e apresentações de realidade virtuais para crianças em tratamento contra o câncer. Eu estou terminando engenharia da computação e eu me sinto bastante satisfeito.

A partir do trecho destacado, pode-se inferir o processo de transição da competência para a expertise. Ou seja, o movimento de ultrapassagem do conhecimento dos fundamentos de um domínio específico para a socialização inicial na cultura, com processos de divulgação e socialização do saber desenvolvido. O PTM proporcionou a Allan Turing a oportunidade de transformação das habilidades aprendidas em produtos com impacto social, ferramentas tecnológicas que implicam na melhoria da qualidade de vida e redução do sofrimento de crianças em tratamento quimioterápico, bem como em material de divulgação científica para a sociedade em geral.

Neste último trecho narrativo é possível vislumbrar o gérmen do movimento de transição da experiência para a eminência, caracterizado pela socialização do indivíduo em um campo específico do conhecimento e pelo compromisso com o bem-estar global e com a sustentabilidade:

Para me 'formalizar' ainda mais eu quero me inscrever... quero conseguir fazer algum... alguns hackathons ... entre querer hackear e participar de hackathons... é a melhor opção quando se trata de proteger o planeta... Sim, eu quero ajudar diversas causas (sic). 


\section{Caso Clínico 2: Bill Gates - AH/SD e Vulnerabilidade Social}

Bill Gates ingressou no PTM aos 16 anos quando cursava o $1^{\circ}$ ano do ensino médio, tendo estudado toda a vida escolar em instituição pública numa cidade do interior do Rio Grande do Norte $(\mathrm{RN})$, caracterizada pela escassez de recursos econômicos e educacionais. Este cenário levou Bill a abandonar a cidade e viver na capital do estado em busca de oportunidades que pudessem atender suas necessidades, interesses e demandas.

Atualmente, Bill está com 18 anos, reside em Natal-RN e concluiu o ensino médio a partir de uma prova ofertada pelo Ministério da Educação para certificação referente a esse nível de escolaridade. A sua produção narrativa referente ao Eixo 1 - vivências relacionadas à escola e família - refletem as dificuldades na adequação às regras homogêneas de desenvolvimento e de aprendizagem. A escola é apontada como única via de acesso ao conhecimento, e este último como um bloco unitário, moldado à imagem e semelhança de todos os estudantes, como pode ser analisado na narrativa de Bill Gates:

Eu era aluno de fundão e os professores não gostavam muito de mim, mas não era culpa minha, era que as aulas eram lentas e eu não podia ir para casa. Aí quando eu comecei a tentar fazer coisa úteis da vida e não só vegetar e fazer o básico pra passar... aí a escola passou a não ser só neutra na minha vida e lenta, começou a ser um estorvo gigantesco. Quando eu desisti da escola, entre aspas, porque ela desistiu de mim primeiro, eu só disse “Ok, não vou perder meu tempo aqui, eu não quis ser um nada na vida, eu vi que ali não era lugar pra mim".

Bill Gates destaca ainda o sofrimento inerente à constatação do cerceamento da escola aos seus interesses:

Antes de ter livros obrigatórios na escola, no começo do fundamental quando não tinha isso, eu lia bastante. Depois começaram a obrigar livros e eu parei de ler por causa disso, porque tinha que ler os livros da escola, não podia ler os livros que eu queria...quando eu comecei a querer fazer algo útil da minha vida ao invés de só ir pra escola virou um tormento gigantesco, era literalmente de dar crises de ansiedade, o coração bater mais rápido, doer parecendo um infarto.

De forma similar, a narrativa produzida por Bill Gates revela que não houve e não há compreensão da família acerca de suas necessidades e acolhimento devido aos seus projetos:

Minha mãe é professora... ela é... surtou um pouquinho quando eu reprovei a primeira vez e quando eu decidi largar a escola... ela nunca aceitou de fato. Até hoje ela não aceita que eu não dou tanto valor para o ensino formal assim, mas não é assim. Eu gosto muito das coisas que são usadas na escola, mas eu acho que elas são dadas da forma errada.

Por fim, Bill Gates destaca a importância de diferentes atores em sua trajetória. Conhecimento produzido onde não se esperava, prazer nas novas descobertas para além dos muros da escola e o aperfeiçoamento de seu talento em TI junto ao PTM. Em suas palavras: "[...] eu aprendi muito mais depois que eu larguei a escola, principalmente sobre o que eu queria da vida e tal. Mesmo em conteúdo eu aprendi muito mais".

A narrativa do jovem revela o quanto a escola tem falhado no seu papel de propulsora do desenvolvimento e da aprendizagem. Destaca a importância de programas diferenciados de intervenções que considerem as áreas de forças e fraquezas do aluno, pois só assim será capaz de motivar e catapultar o desempenho acadêmico dos alunos com AH/SD (CREPEAU-HOBSON, BIANCO, 2013; LEE, OLENCHAK, 2014). 
Por outro lado, sua narrativa reforça o quanto o PTM tem sido o cenário no qual Bill Gates pode exercitar o aprendizado baseado e estruturado em projetos que considerem seus interesses e seu tempo:

Eu não acreditava mais que a escola era pra mim, eu voltei... fracassei. Não fracassei! A escola fracassou comigo! [...] A coordenadora era muito esforçada, mas ainda tem muito gesso no ensino fundamental e médio. Ela viu o Edital do Talento nas férias de julho, daí eu fiz. Aí ao longo do tempo eu já tomei interesse pelo mundo acadêmico, mais formal, por ver coisas aqui, pagando disciplinas aqui, que me "causou" muita energia. Difícil pra caramba, era bem legal, mas ao mesmo tempo era bem difícil e bem legal ao mesmo tempo. Toda flexibilidade do BTI especificamente, todo o contato com essas coisas, eu pensei: "Ok! Me parece legal agora, não parece mais chato e inútil”.

\section{Caso Clínico 3: Margareth Hamilton - AH/SD e Transtorno de Humor}

Margareth Hamilton tem 18 anos, está na graduação no curso de Bacharelado em Tecnologia da Informação em uma universidade pública do RN. Ela iniciou sua participação no Programa aos 14 anos quando cursava o ensino médio. Margareth foi identificada com AH/SD aos dois anos de idade nos EUA, quando começou a ler em sua língua materna (inglês) e na língua materna de seus pais (português). A identificação precoce possibilitou que ela pudesse ser estimulada e motivada desde os primeiros anos da infância, não apenas pelos familiares, mas também pelos professores e psicólogos da escola em que estudava, para que ela não perdesse o interesse escolar. A importância da escola e da família nos anos iniciais de Margareth são claramente ressaltados em sua produção narrativa:

Eu fui diagnosticada com altas habilidades muito nova, meus pais já perceberam desde cedo, e eu frequentei várias escolas... recebi bastante apoio tanto dos professores, como dos psicólogos na escola. Eles sempre me motivaram a continuar estudando, a nunca perder o interesse e a me desenvolver nas áreas que eu gostava... (risos) e que são muitas.

Porém, quando os pais retornaram ao Brasil e ela foi matriculada aos doze anos em uma escola particular tradicional da cidade de Natal, instalou-se um quadro de desmotivação, que gerou grande preocupação para os pais. A narrativa de Margareth Hamilton revela a perda paulatina de interesse pela escola e pelas relações sociais:

No fundamental II eu mudei para outra escola, que apesar de ser uma escola muito boa não correspondeu os meus interesses, não me estimulavam muito com as minhas altas habilidades, eu me sentia muito desmotivada certas horas, eu perdi bastante o interesse pela escola, eu perdi realmente muito tempo, digamos, nisso ...quando eu poderia estar desenvolvendo meu potencial. Eu só estava assistindo as mesmas aulas e foi muito difícil para mim conseguir voltar a me adaptar ao ensino tradicional.

Posteriormente em sua narrativa, ela detalha quais os aspectos vivenciados na escola que lhe causavam sofrimento e desmotivação:

Não é um sistema que foi muito feito para os alunos diferentes, seja quem for... não, para alguém que quer desenvolver seu real potencial, que quer fazer algo com o que tem. Não é um sistema muito eficiente, eles tratam todos como se fossem iguais e ninguém é igual e todo mundo. Quer ver algo? Para eles todos 
têm a mesma quantidade de matérias no mesmo fundamento. Se você quiser se aprofundar em algo você não vai ter tanto apoio quanto gostaria de aprofundar. Então é algo muito difícil e foi um período bastante turbulento para mim na área acadêmica, eu sentia muito desinteresse, eu não queria muitas aulas, eu tive um baixo desempenho nas provas. Pra ser sincera, eram matérias que eu até gostava, assim, as áreas exatas, mas não era uma aprofundadas de um jeito que me causasse interesse, não era uma didática interessante, eu tentei fazer estudos a parte de algumas áreas, mas não foi muito suficiente, eu não sou muito autodidata, ainda estou tentando trabalhar nessa área, desde pequena eu sempre tive interesse em aprender fora da escola, mas foi um pouco difícil essa atividade, eu ainda não tinha tanto essa habilidade.

Por fim, Margareth Hamilton descreve o lugar do PTM na sua trajetória de vida até este momento, destacando a inflexão decorrente de sua entrada no programa:

\begin{abstract}
Então quando eu vim para o Talento foi aí que eu consegui tentar regular essa perda. O padrão de ensino brasileiro, se eu puder generalizar, não era algo que me causava muito interesse. Procurei já diversas escolas, que eles falavam que eram as mais indicadas para superdotados. A gente falou com muitas pessoas, muitos professores. Não tinha nenhuma escola realmente apta para me ajudar nisso, acho que o melhor que teria sido, seria talvez, o Talento mesmo, mas ainda não tinha o Talento, então foi um período bastante difícil, entre dois ou três anos de quando eu cheguei e foi algo... foi um momento muito difícil para conseguir conciliar os meus interesses com os meus estudos... O ensino brasileiro foi feito para provas, para ingressar na universidade. Por mais que isso seja admirável, você educar um aluno para a universidade, você vai criar um aluno apenas para isso, mas quando ele entrar na universidade ele vai ver o que quer. Mas você vai perder anos da vida dele, fazendo o que ele não quer. Talvez esse aluno só vá se desenvolver na universidade. Talvez eu seja melhor fazendo um projeto, como a maioria de nós somos aqui no Talento, ou talvez olimpíadas, como alguns são. Com o Talento eu consegui voltar a me interessar nas matérias, mas foi algo um pouco difícil, eu tive que me esforçar bastante para voltar a ter interesse.
\end{abstract}

\title{
DISCUSSÃO
}

O objetivo deste estudo foi explorar as experiências vividas por três jovens com AH/SD imersos em contextos distintos de adversidades, a saber, a dupla-excepcionalidade (AH/SD e TEA), a vulnerabilidade social e os transtornos de humor. A investigação aqui avançada buscou elucidar as vozes destes jovens e estas revelaram pontos de concordância e idiossincrasias, como era o esperado se considerarmos as suas individualidades.

Certamente o ponto que une todas as narrativas refere-se às vivências negativas relacionadas à escola, notadamente nos anos iniciais. No âmbito das $\mathrm{AH} / \mathrm{SD}$, constata-se que o ensino tradicional falha, na maioria das vezes, por tornar-se desinteressante, uma vez que tende a ignorar o papel ativo do aluno no processo de aprendizagem. Por vezes, os métodos educacionais homogeneízam interesses e percursos, cerceando a criatividade e as rotas alternativas de construção de conhecimento. Como resultado, o Brasil termina por desperdiçar os seus talentos, sem que haja programas específicos que promovam o desenvolvimento das potencialidades destes jovens, traduzindo-as em ações de pesquisa e inovação (HAZIN et al., 2015).

Estudos abrangentes com essa população são necessários para a compreensão do perfil de funcionamento das funções psicológicas superiores em subgrupos específicos, auxiliando na 
identificação de potenciais e déficits, com desdobramentos importantes para a proposição de intervenções clínicas e educacionais. Faz-se igualmente relevante o acompanhamento e intervenção junto a este grupo, de modo a proporcionar o desenvolvimento de habilidades co-cognitivas (comportamentais, sociais, executivas e metacognitivas) que contribuam para o sucesso profissional, uma vez que a presença de altas habilidades não garante o desenvolvimento pleno de competências em nenhuma área específica do conhecimento humano.

Um segundo ponto a ser explorado refere-se às habilidades sociais, ao isolamento social o que podem impactar a autoestima de indivíduos com AH/SD. Pesquisadores são congruentes ao destacar a importância do suporte familiar ao longo da trajetória destas crianças e jovens. A narrativa de Margareth ressalta o papel decisivo dos pais, na busca por escolas adequadas, atividades extras, suportes profissionais. O estilo parental forte, o apoio contínuo auxilia no desenvolvimento inicial de talentos, promovendo o enriquecimento, acreditando no potencial da criança e defendendo continuamente a complexidade de seus filhos (AMRAN, MAJID, 2019).

Por fim, destaca-se as produções narrativas referentes ao PTM, foco maior deste estudo. A maior intenção desta investigação era dar vOz aos participantes e compreender se a proposta avançada cumpria com o objetivo primeiro, proposto em seu documento fundante, ou seja, ser espaço de desenvolvimento de talentos no domínio da tecnologia da informação. As narrativas sugerem que o PTM promoveu uma significativa inflexão em suas rotas de desenvolvimento. As falas produzidas nos alertam para a necessidade de formação de professores, para a criação intencional de ambientes educacionais afirmativos (ambientes educacionais livres de estresse e ansiedade), ouvindo e apoiando as crianças e os jovens com AH/SD.

Os alunos com AH/SD são considerados público-alvo da educação especial, assim como as pessoas com deficiências ou transtornos globais do desenvolvimento. Por conseguinte, têm direito ao atendimento educacional especializado necessário, com vistas a facilitar sua efetiva educação, segundo as diretrizes do Decreto n. 7.611, de 17 de novembro de 2001 (BRASIL, 2011), bem como garantir o acesso a medidas de apoio individualizadas e efetivas, em ambientes que maximizem seu desenvolvimento acadêmico e social, de acordo com a meta de inclusão plena.

$\mathrm{O}$ aumento concreto em termos de identificação da população de AH/SD alerta para a ampliação das ações educativas no país, no sentido do reconhecimento e estímulo desse grupo, e de atender, às suas necessidades afetivas, comportamentais e cognitivas especiais. No contexto atual, é imperativo que as políticas públicas estejam alinhadas às evidências científicas na área e que considerem o potencial desses alunos para o desenvolvimento tecnológico, cultural e educacional do país. Reconhecer, estimular e aproveitar talentos humanos em desenvolvimento ou em potencial torna-se uma grande responsabilidade de todas as esferas: família, escola e sociedade.

Embora se observem avanços nos estudos da educação especial no contexto das altas habilidades, muito ainda precisa ser feito, em termos de identificação, compreensão e intervenção junto a esse grupo. Conhecer as características deste perfil e estimular o desenvolvimento potencial destes alunos representa um desafio que exige comunicação e esforço científico conjunto.

\section{CONSIDERAÇÕES FINAIS}

A Organização Mundial da Saúde (OMS) estima que 3,5\% a 5\% da população escolar são estudantes que apresentam características de AH/SD. Entretanto, para esse índice foram consideradas apenas altas habilidades nas áreas linguística e lógico-matemática, tradicionalmente avaliadas neste contexto. Quando incluídos outros aspectos à avaliação de superdotados, como 
liderança, criatividade, competências psicomotoras e artísticas, as estatísticas tendem a ser bem mais expressivas, abarcando uma porcentagem de $15 \%$ a 30\% da população (RENZULLI, 2004).

No entanto, constata-se ainda o desperdício dos talentos brasileiros, as altas taxas de insucesso acadêmico e de sofrimento psíquico vivenciados por estes indivíduos. Buscando contribuir com o desenvolvimento de jovens talentos na área da tecnologia da informação, o Instituto Metrópole Digital da UFRN lançou em 2015 o Programa Talento Metrópole. Este tem como meta ofertar formação de qualidade que contemple os interesses dos estudantes, considerando seus potenciais, rompendo com a hierarquia e rigidez do ensino tradicional. Por fim, o programa se propõe a explorar possibilidades de carreira profissional relacionadas a este domínio, com vista à inserção criativa no mundo do trabalho e à participação social solidária.

Espera-se que as narrativas produzidas por jovens vinculados ao PTM e que demonstram o papel desse programa na estruturação de novas rotas de desenvolvimento e na promoção de novas vivências para esses jovens possam inspirar novos programas. Com programas como este, pode-se sonhar com um país que deixe de desperdiçar seus talentos, fomentando ações que transformem todo o potencial de crianças e jovens em ações que garantam um mundo mais igualitário e com melhor qualidade de vida para todos.

\section{REFERÊNCIAS}

AMRAN, Hannah Aqilah; MAJID, Rosadah Abd. Learning Strategies for Twice -Exceptional Students. International Journal of Special Education, Malaysia, 33(4), p. 954-976, 2019.

BLOOM, Benjamin Samuel. Developing talent in young people. New York: Ballantine Books, 1985.

CREPEAU-HOBSON, Franci; BIANCO, Margarita. Response to Intervention: Promises and Pitfalls for Gifted Students with Learning Disabilities. Intervention in School and Clinic, 48(3), p. 142151, jan. 2015. Disponível em https://doi.org/10.1177/1053451212454005. Acesso em fev. 2021.

FOLEY-NICPON, Megan; ASSOULINE, Susan G.; COLANGELO, Nicholas. Twiceexceptional learners: Who needs to know what? Gifted Child Quarterly, Iowa, 57(3), p. 169-180, maio/2013. Disponível em https://doi.org/10.1177/0016986213490021. Acesso em fev. 2021.

GAGNÉ, François. The Differentiated Model of Giftedness and Talent. In: RENZULLI, Joseph; GUBBINS, Jean; MCMILLEN, Kristin S.; ECKERT, Rebecca D; LITTLE, Catherine A. (eds.). Systems and models for developing programs for the gifted and talented. Mansfield: Creative Learning Press, 2009. p. 165-192.

KIM, Jeong-Hee. Understanding narrative inquiry: the crafting and analysis of stories as research. Thousand Oaks: Sage, 2016.

LEE, Kelly M; OLENCHAK, F. Richard. Individuals with a gifted / attention deficit / hyperactivity disorder diagnosis: identification, performance, outcomes, and interventions. Gifted Education International, Texas, 31 (3), p. 185-189, fev. 2014. Disponível em https://doi.org/10.1177/0261429414530712. Acesso em fev. 2021.

MATTHEWS, Dona. J; FOSTER, Joanne. F. Mystery to mastery: Shifting paradigms in gifted education. Roeper Review, Londres, 28(2), p. 64-69, jan. 2005. Disponível em https://doi.org/10.1080/02783190609554340. Acesso em fev. 2021.

MILLER, Angie L. Conceptualizations of Creativity: Comparing Theories and Models of Giftedness. Roeper Review, Flórida, 34(2), p. 94-103, mar. 2013. Disponível em https://doi.org/10.1080/02783193.2012.660683. Acesso em fev. 2021. 
OLSZEWSKI-KUIBLIUS, Paula; THOMSON, Dana. Talent development as a framework for gifted education. Gifted Child Today, Boston, 38 (1), p. 49-59, jan. 2015.

RENZULLI, Joseph. O que é esta coisa chamada superdotação, e como a desenvolvemos? Uma retrospectiva de vinte e cinco anos. Educação, Porto Alegre, 1(52), p. 75-131, abr. 2004.

RONSKLEY-PAVIA, Michelle; GROOTENBOUER, Peter; PENDERGAST, Donna. Privileging the Voices of Twice-Exceptional Children: An Exploration of Lived Experiences and Stigma Narratives. Journal for the Education of the Gifted, Southport, Queensland, 42(1), p. 4-34, dez. 2019.

SCHWANDT, Thomas. Constructivist, interpretivist approaches to human inquiry. In: LINCOLN, Y. S. (ed.). Handbook of qualitative research. Thousand Oaks, CA: Sage, 1994. p. 118-137. SUBOTNIK, Rena; OLSZEWSKI-KUBILIUS, Paula; WORRELL, Frank. Talent development as the most promising focus of giftedness and gifted education. In: PFEIFFER, Steven I.; SHAUNESSY-DEDRICK, Elizabeth; FOLEY-NICPON, Megan (ed.). APA bandbook of giftedness and talent. Massachusetts: American Psychological Association, 2018. p. 231-245. Disponível em https://doi.org/10.1037/0000038-015. Acesso em fev. 2021.

SUBOTNIK, Rena; JARVIN, Linda. Beyond expertise: conceptions of giftedness as great performance. In: STERNBERG, Robert J.; DAVIDSON, Janet (ed.). Conceptions of giftedness. New York: Cambridge University Press, 2005. p. 343-357.

SUBOTNIK, Rena; OLSZEWSKI-KUBILIUS, Paula; WORRELL, Frank. Rethinking giftedness and gifted education: a proposed direction forward based on psychological science. Psychological Science in the Public Interest, California, 12 (1), p. 3-54, set. 2011. Doi:10.1177/1529100611418056.

TANNENBAUM, Abraham. Nature and nurture of giftedness. In: COLANGELO, Nicholas; DAVIS, Gary A. (ed.). Handbook of gifted education. New York, NY: Pearson, 2003. p. 45-59.

HAZIN, Izabel; FALCÃO, Jorge; RÊGO, Ivonildo; GOMES, Apuena; ANDRADE, P., ... REIS, Juliana; WENICE, Mayara. High Abilities and Information Technologies: The Talento Metrópole Brazilian Program. Creative Education, 6, p. 647-653, maio 2015.

YOUNG, David. Interpretivism and education law research: a natural fit. Education Law Journal, 18, p. 203-219, fev. 2009.

Submetido em fevereiro de 2021 Aprovado em abril de 2021

\section{Informações das autoras}

Juliana Teixeira da Camara Reis

Universidade Federal do Rio Grande do Norte

E-mail:psi.julianareis@gmail.com

ORCID: https://orcid.org/0000-0001-7645-6176

Link Lattes: http://lattes.cnpq.br/4896546595634321

Priscila Magalhães Barros Felinto

Universidade de Brasília

E-mail: priscilamagalhaesb@gmail.com

ORCID: https://orcid.org/0000-0002-6989-5514

Link Lattes: http://lattes.cnpq.br/3503480700332244 
Izabel Hazin

Universidade Federal do Rio Grande do Norte

E-mail: izabel.hazin@gmail.com

ORCID: https://orcid.org/0000-0002-4045-8628

Link Lattes: http://lattes.cnpq.br/5496201609189471

Revista Teias v. 22 • n. 66 • jul./set. 2021 • Seção temática Programas e práticas pedagógicas na educação especial e inclusiva 